\title{
R-etodolac induces E-cadherin and suppresses colitis-related mouse colon tumorigenesis
}

\author{
TAKUYA INOUE $^{1}$, MITSUYUKI MURANO ${ }^{1}$, YUKIKO YODA ${ }^{1}$, TAKANORI KURAMOTO ${ }^{1}$, KAZUKI KAKIMOTO $^{1}$, \\ KUMI ISHIDA $^{1}$, KEN KAWAKAMI ${ }^{1}$, YOSUKE ABE ${ }^{1}$, EIJIRO MORITA ${ }^{1}$, NAOKO MURANO ${ }^{1}$, \\ SATOSHI TOKIOKA ${ }^{1}$, KENTARO MAEMURA ${ }^{2}$, EIJI UMEGAKI ${ }^{1}$ and KAZUHIDE HIGUCHI ${ }^{1}$ \\ ${ }^{1}$ Second Department of Internal Medicine, and ${ }^{2}$ Department of Anatomy, Osaka Medical College, \\ 2-7 Daigakumachi, Takatsuki city, Osaka 569-8686, Japan
}

Received June 1, 2010; Accepted August 11, 2010

DOI: 10.3892/or_00001009

\begin{abstract}
Colorectal cancer is one of the most serious complications of ulcerative colitis (UC), and the risk of UCassociated neoplasia increases as the region and duration of the disease increase. Selective cyclooxygenase (COX)-2 inhibitors effectively diminish carcinogenesis in a murine UC model. However, this may exacerbate colitis. The selective COX-2 inhibitor etodolac is marketed as a racemic mixture of the R- and S-enantiomers. The biochemical and pharmacological effects of etodolac are caused by the S-enantiomer, while the R-enantiomer lacks COX-inhibitory activity. In this study, we evaluated the effect of R-etodolac on colitisrelated mouse colon tumorigenesis. The mice received 1,2-dimethlhydrazine (DMH), and then chronic colitis was induced by administration of two cycles of DSS (each cycle: $3 \%$ DSS for 7 days followed by distilled water for 14 days). The mice were sacrificed 28 days after the completion of both cycles. Mice were divided into the following groups: group A served as a disease control; group B received a low (2-mg/kg) dose of R-etodolac every 3 days during the entire period; group $\mathrm{C}$ received a high $(10-\mathrm{mg} / \mathrm{kg})$ dose of R-etodolac on the same schedule as group $\mathrm{B}$; and group D served as a normal control. Administration of R-etodolac decreased the disease activity index during the DSS administration cycle. The mean number of tumors was $17.8,15.2,6.0$, and 0 in groups A-D, respectively. In group C, R-etodolac significantly suppressed the occurrence of neoplasia $(\mathrm{p}<0.05)$. Although $\mathrm{R}$-etodolac treatment did not affect COX-2 expression, it significantly enhanced expression of E-cadherin in both
\end{abstract}

Correspondence to: Dr Mitsuyuki Murano, Second Department of Internal Medicine, Osaka Medical College, 2-7 Daigakumachi, Takatsuki city, Osaka 569-8686, Japan

E-mail: in2068@poh.osaka-med.ac.jp

Key words: dextran sulfate sodium, ulcerative colitis, cancer, etodolac, E-cadherin neoplastic lesions and background mucosa (i.e., lesionfree colon). Thus, administration of R-etodolac exerts a suppressive effect on the development of neoplasia in a murine model of DSS-induced colitis without exacerbation of the colitis. These results suggest that R-etodolac could be useful in the prevention of UC-associated neoplasia.

\section{Introduction}

Non-steroidal anti-inflammatory drugs (NSAIDs) inhibit cyclooxygenase (COX) activity and have previously been considered as promising agents for the prevention of colon tumors, based upon both epidemiological and animal model data (1-4). To date, two isoforms of COX, COX-1 and COX-2, have been identified. COX-1 is constitutively expressed in most tissues, including the gastrointestinal tract, at a relatively stable level, and plays a role in various physiological functions, such as protection of the gastrointestinal tract from injury $(5,6)$. COX-2 is an inducible COX that is up-regulated in response to various stimuli, such as interleukin-1 and tumor necrosis factor $(5,6)$. COX-2 contributes to the reparative process that follows mucosal injury in the gastrointestinal tract, and is thought to play an important role in abnormal cell proliferation.

Patients with ulcerative colitis (UC) exhibit an increased risk for development of cancer of the colon and rectum; this risk increases as the affected region and disease duration increase. The incidence of UC-associated dysplasia and cancer is higher than that of sporadic colorectal cancer, and the necessity of chemoprevention of UC-associated dysplasia and cancer has been acknowledged (7). COX-2 inhibitors are known to suppress sporadic colorectal cancer, but it remains unknown whether selective COX-2 inhibitors exhibit a preventive effect in UC-associated neoplasia. Indeed, it has been widely believed that NSAIDs may trigger UC relapses and should not be given to patients with a history of inflammatory bowel disease due to the possibility of colitis exacerbation $(8,9)$. In our previous study, we developed an experimental murine model of UC and evaluated the influence of a selective COX-2 inhibitor in the active and/or remission phases that mimic human UC disease phases. In that study, COX-2 inhibitor treatment during the active phase 


$$
\text { day } 0
$$

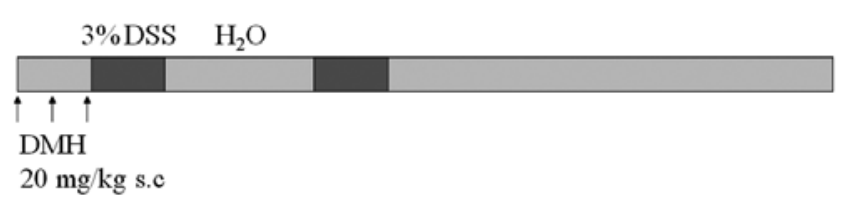

Figure 1. Protocol for inducing colorectal tumors in mice via administration of DMH and $3 \%$ DSS.

exacerbated colitis, and did not appear to have a preventive effect on colorectal carcinogenesis (10).

The selective COX-2 inhibitor etodolac is marketed as a racemic mixture of the $\mathrm{R}$ - and $\mathrm{S}$-enantiomers, which are not metabolically interconvertible (11). The biochemical and pharmacological effects of etodolac are elicited by the S-enantiomer, while the R-enantiomer lacks COX-inhibitory activity (12). Therefore, R-etodolac has the potential advantage of avoidance of COX-2 inhibitory adverse effects. Moreover, R-etodolac has been reported to induce upregulation of E-cadherin, and has antitumor activity against hepatoma and bladder cancer cells $(13,14)$. However, no reports describing any anti-tumor effects of R-etodolac in colitis-related tumors have been published. In this study, we developed an experimental murine model of longstanding UC, and evaluated the effect of R-etodolac on colitis-related mouse colon tumorigenesis.

\section{Materials and methods}

Animals. Six-week-old female BALB/c mice (CELA Japan, Tokyo, Japan) weighing 20-25 g were used in this study. The animals were maintained in an animal colony with controlled temperature $\left(23^{\circ} \mathrm{C}\right)$ and light $(12 / 12$-h light and dark cycle) at the Osaka Medical College, Osaka, Japan, and were permitted free access to standard mouse chow pellets (MM-3, Funabashi, Chiba, Japan) and tap water.

Protocol for induction of colorectal tumors and experimental procedures. The design for inducing colonic tumors is shown in Fig. 1. At the age of 6 weeks, the mice were given 1,2dimethylhydrazine (DMH; Wako Pure Chemical Industries, Osaka, Japan) at a dose of $20 \mathrm{mg} / \mathrm{kg}$ body weight subcutaneously three times within 1 week. Starting 1 week after the DMH injection, chronic colitis was induced in mice by administration of two cycles of dextran sulfate sodium (DSS; molecular weight 5000; Meitou Sangyou, Osaka, Japan) (each cycle: $3 \%$ DSS for 7 days followed by distilled water for 14 days). The mice were sacrificed 28 days after the completion of both cycles.

The mice were divided into the following groups: group A served as a disease control; group B received a low (2-mg/kg) dose of R-etodolac (kindly provided by Nippon Shinyaku Co., Ltd., Kyoto, Japan); group C received a high (10-mg/kg) dose of R-etodolac; and group D received no agents (including DSS) and served as a normal control. R-etodolac was dissolved in $100 \%$ ethanol and diluted to a suitable concentration with a 5\% aqueous solution of Arabic gum. The solution of R-etodolac was given to mice by oral gavage, every 3 days during the entire experimental period (15). After death, the entire colorectum from the colocecal junction to the anal verge was excised and rinsed in phosphatebuffered saline (PBS). The specimen was opened longitudinally and was fixed on a cork board in $10 \%$ formalin. Then, the specimen was stained with $0.2 \%$ methylene blue and colonic tumors were counted under a stereomicroscope $(10,16)$. Histopathological examination was performed on paraffin-embedded sections after hematoxylin and eosin staining. Colonic mucosal dysplasia and cancer were diagnosed according to the criteria described by Riddell et al (17).

Evaluation of severity of clinical colitis. Disease activity index (DAI) was determined in all animals during the first cycle of DSS administration by scoring body weight, stool hemocult reactivity, or presence of gross blood and stool consistency in accordance with the method described by Murthy et al (18). This scoring method is a comprehensive functional measure that correlates well with the degree of inflammation. The individuals who examined mice and determined the DAI were blinded to the experimental group assignments.

Immunohistochemistry. Expression of COX-2 and E-cadherin in the intestinal mucosa was assessed by the labeled streptavidin-biotin method using an LSAB kit (Dako, Carpinteria, CA, USA) with microwave accentuation. Each segment was fixed in $10 \%$ formalin, embedded in paraffin wax, and cut into tissue sections of 4-mm thickness. Tissue sections were mounted on microscope slides, deparaffinized in xylene ( $3 \times 3 \mathrm{~min}$ ), and dehydrated with $100 \%$ ethanol. After washing with PBS, sections were placed in $10 \mathrm{mmol} / \mathrm{l}$ citrate buffer ( $\mathrm{pH} \mathrm{6.0)}$ ) and heated to $80^{\circ} \mathrm{C}$ for $10 \mathrm{~min}$ in a microwave oven. After washing with PBS, endogenous peroxidase activity was blocked using $0.3 \%$ hydrogen peroxide in $10 \%$ methanol for $30 \mathrm{~min}$, and blocking reagent was added for $15 \mathrm{~min}$. Sections were incubated at $4^{\circ} \mathrm{C}$ overnight in the primary antibody (rabbit anti-COX-2 IgG: Cayman Chemical, Ann Arbor, MI, USA; rat anti-E-cadherin IgG: Invitrogen, Camarillo, CA, USA). After washing with PBS, sections were incubated with a biotinylated immunoglobulin antibody (Dako) at room temperature for $30 \mathrm{~min}$. Sections were then washed in PBS and visualized using streptavidin-biotin horseradish peroxidase (Dako) and 3,3' diaminobenzidine (Dako). Finally, sections were counterstained with hematoxylin, dehydrated, and cover-slipped with permanent mounting medium for microscopic examination (10).

Immunohistochemical evaluation. We used a scoring system to semiquantitatively evaluate immunoexpression. The colonic epithelium and stroma of each sample were evaluated for staining. Sections were examined at a magnification of $\mathrm{x} 80$, which allowed assessment of the staining intensity of the portion of the epithelium and stroma encompassed within the microscopic field. Subsequently, a magnification of $x 400$ was used to score the stained epithelium and stromal cells within each segment. 
The scoring system was adapted from that described by Yamauchi et al (19) as follows: staining intensity (0, negative; 1 , weak; 2 , moderate; and 3 , strong) $\mathrm{x}$ stained area $(0,<10 \%$ of cells in the microscopic field; $1,<30 \%$ of cells; $2,30-70 \%$ of cells; and 3, $>70 \%$ of cells). The product provided scores of 0-9 for both the colonic epithelium and stroma, and scores in each region were added to provide a total staining score for which the maximum score was 18 .

Analysis of COX-2 mRNA expression by reverse-transcription PCR. To evaluate COX-2 mRNA expression in the background mucosa, a small amount of intestinal tissue samples was removed from lesion-free murine colon under a stereomicroscope, frozen in liquid nitrogen, and stored at $-80^{\circ} \mathrm{C}$ until RNA isolation. Total RNA was extracted from tissue samples using a total RNeasy mini-Kit (Qiagen $\mathrm{GmbH}$, Hilden, Germany). Reverse-transcription PCR was performed with the High Fidelity PrimeScript RT-PCR Kit (Takara Bio Inc., Shiga, Japan) according to the manufacturer's instructions. The sequences of sense and antisense primers for mouse COX-2 are 5'-ACCCCCTGCTGCCCGACA CCT-3' and 5'-CCAGCAACCCGGCCAGCAATC-3', respectively, which yields a 136-base-pair PCR product. For mouse glyceraldehyde-3-phosphate dehydrogenase (G3DPH), a constitutively expressed gene, sense and antisense primer sequences were 5'-TGAAGGTCGGTGTGAA CGGATTTGGC-3' and 5'-CATGTAGGCCATGAGGT CCACCAC-3', respectively, giving rise to a 983-base-pair PCR product. An aliquot of the reverse transcription reaction product served as a template for $35 \mathrm{PCR}$ cycles consisting of 1-min denaturation at $94^{\circ} \mathrm{C}, 0.5 \mathrm{~min}$ annealing at $56^{\circ} \mathrm{C}$, and 1 -min extension at $72^{\circ} \mathrm{C}$ in a thermal cycler. A portion of the PCR mixture was electrophoresed in a $1.5 \%$ agarose gel in Tris-EDTA-acetic acid buffer, and the gel was stained with ethidium bromide and photographed (20).

Statistical analysis. All results are expressed as mean \pm SD. Comparisons were performed using one-way ANOVA or Kruskal-Wallis followed by Fisher's PLSD test. Statistical significance was defined as $\mathrm{P}<0.05$.

\section{Results}

Changes of DAI. Most of the mice who received 3\% DSS exhibited loose and hemocult-positive stools 4 days after DSS administration. Clinical symptoms of colitis including bloody stool, diarrhea, and loss of body weight progressed further until day 8 . These signs gradually disappeared during the period of drinking distilled water without DSS for the following 14 days. Accordingly, the DAI gradually increased until day 8 and then reverted to normal by day 21 as previously described (21). Administration of R-etodolac suppressed the DAI, although not to a statistically significant degree (Fig. 2).

Colorectal length and number of tumors. The colorectal length in groups A-D was 8.3 $\pm 0.4,7.6 \pm 0.5,8.2 \pm 0.9$, and $9.4 \pm 0.6 \mathrm{~cm}$, respectively. Colorectal length was significantly shorter in all groups compared to the normal control (group D)

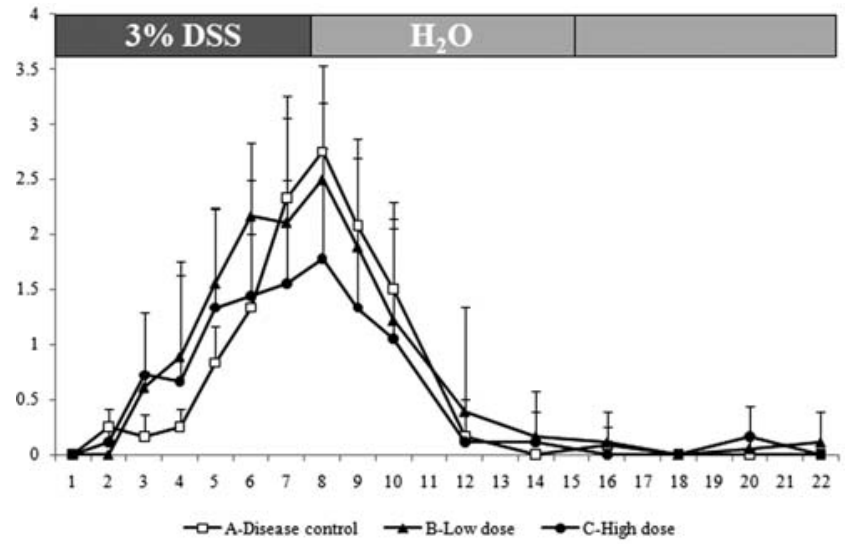

Figure 2. Time course of DAI after the start of DSS administration (n.s vs. group A).

70 days after starting DSS administration. However, administration of R-etodolac did not significantly change the colorectal length. Although the incidence of colonic neoplasia (number of mice with neoplasms) in groups A-C was $100 \%$, the number of tumors/mouse in groups A-C was $17.8 \pm 5.4,15.2 \pm 4.3$, and $6.0 \pm 3.7$, respectively. R-etodolac administration tended to be associated with a lower number of tumors/mouse. In group C, R-etodolac significantly suppressed the occurrence of colon tumorigenesis $(\mathrm{P}<0.05$ compared to group A) (Fig. 3).

COX-2 expression. The COX-2 score of tumors in groups A-C and of normal control colon (group D) was 10.2 \pm 4.0 , $11.4 \pm 2.7,10.2 \pm 3.6$, and $2.4 \pm 0.5$, respectively. Although immunohistochemical evaluation showed diffuse cytoplasmic COX-2 overexpression in tumors and COX-2 scores were significantly increased in groups A-C compared to normal controls, administration of R-etodolac did not result in lower tumor COX-2 scores (Fig. 4). Reverse-transcription PCR analysis revealed COX-2 mRNA expression in lesion-free colon in the disease control mice (group A), although it was not detected in the colons of normal control mice (group D). Up-regulation of COX-2 mRNA in the lesion-free colon was also observed in R-etodolac-treated mice (groups B and C) (Fig. 5). These results suggested that R-etodolac administration does not influence COX-2 expression in the colon.

E-cadherin immunohistochemistry. Immunohistochemical analysis revealed mild to moderate continuous membranous expression of E-cadherin along the lateral cell borders in normal colon epithelial cells. In contrast, dysplastic and cancer cells exhibited weak E-cadherin positivity and a decreased fraction of cells showing membranous staining compared to normal cells. These results are compatible with those of previous reports $(22,23)$. Administration of $\mathrm{R}$-etodolac results in remarkably increased E-cadherin expression in both tumors and lesion-free colon (Fig. 6). E-cadherin scores of tumors in group A-C and normal control colon in group D were 3.4 $\pm 1.1,8.8 \pm 1.6,11.4 \pm 2.7$, and 4.6 \pm 2.1 , respectively. In groups $B$ and $C$, the E-cadherin score was significantly higher than that in group $\mathrm{A}(\mathrm{P}<0.05)$. 

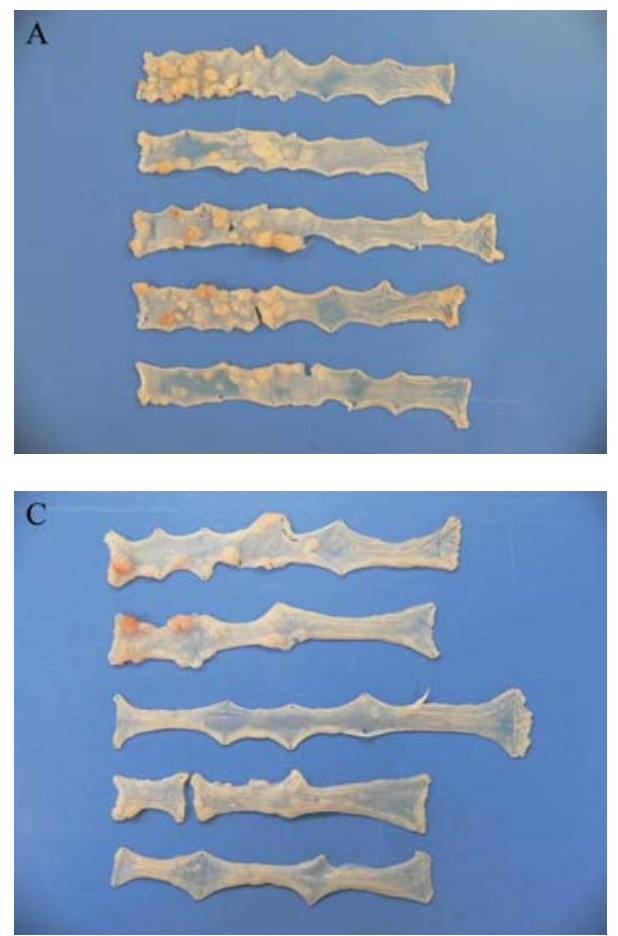
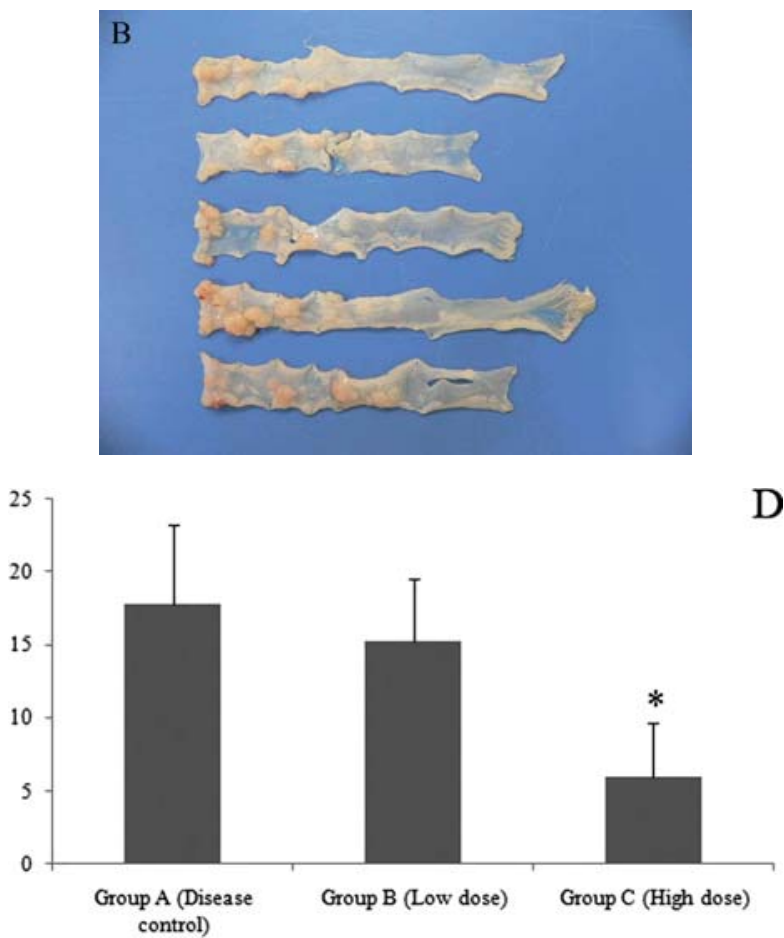

Figure 3. Colorectal tumors in mice. Macroscopic view showing gross lesions in the colon: (A) disease control (group A); (B) low-dose R-etodolac (group B); (C) high-dose R-etodolac (group C). (D) The number of tumors/mouse. In group C, R-etodolac significantly suppressed the occurrence of colon tumorigenesis. ${ }^{*} \mathrm{P}<0.05$ compared to group A.

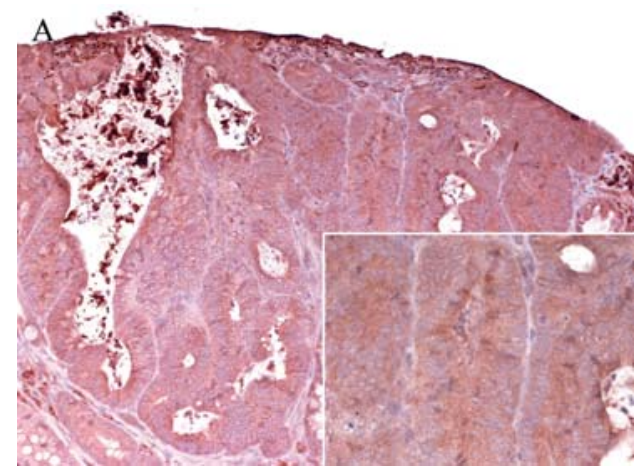

$\mathrm{C}$

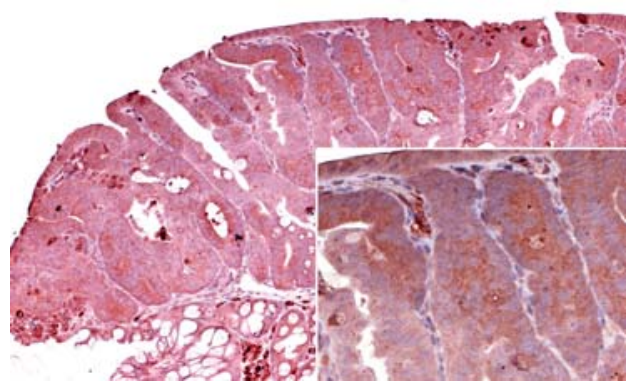

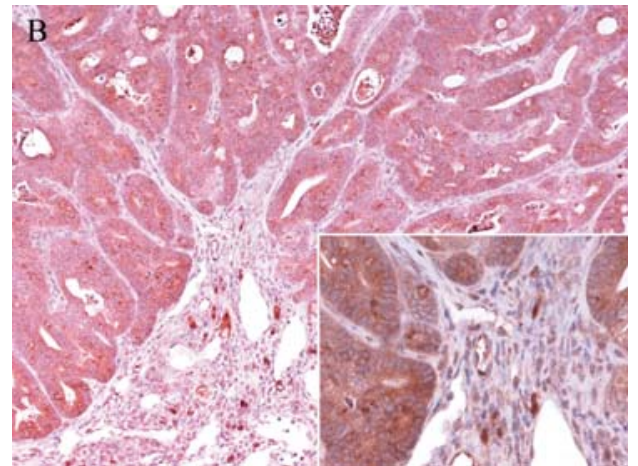

D

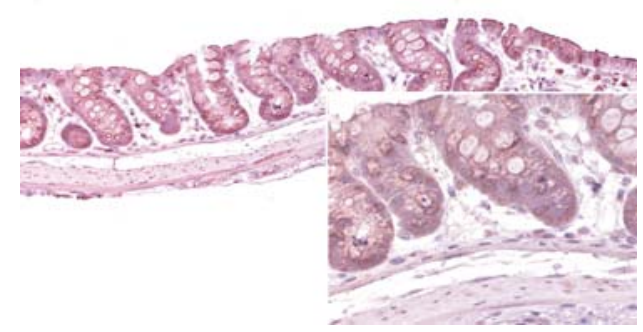

Figure 4. Immunohistochemical analysis of COX-2 expression in the mouse colon. (A) Disease control (group A); (B) low-dose R-etodolac (group B); (C) high-dose R-etodolac (group C); (D) normal control (group D). Original magnification, x200, x400.

\section{Discussion}

Colorectal cancer is one of the most serious complications of ulcerative colitis (UC), and the risk of UC-associated neoplasia increases as the extent and duration of the disease increase. Indeed, the incidence of colorectal cancer in patients with long-standing UC is higher than that of sporadic colorectal cancer (7). Therefore, a treatment that could 


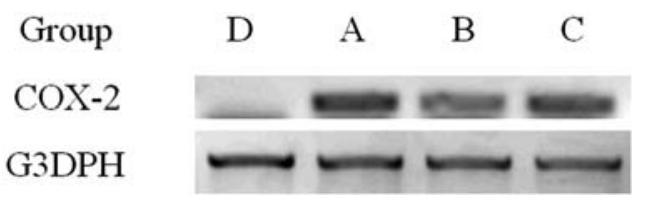

Figure 5. COX-2 mRNA expression in lesion-free colonic mucosa of mice.

prevent UC-associated neoplasia would be of great benefit by obviating the need for surveillance and, in some patients, the need for total colectomy for dysplasia or carcinoma (24).

NSAIDs inhibit COX activity and have previously been considered as promising agents for the prevention of colon tumors based upon both epidemiological and animal model data (1-4). COX-2 is progressively overexpressed during the stepwise sequence from adenoma to cancer, and it is well known that selective COX-2 inhibitors prevent recurrence of adenoma among patients with a history of familial adenomatous polyposis (25). However, the role of selective COX-2 inhibitors in UC-associated neoplasia remains unexplored, because it has been widely believed that these agents may exacerbate UC inflammatory activity (24). To investigate the influence of the selective COX-2 inhibitor nimesulide on the active and/or remission phases that mimic human UC, we previously developed a murine model of long-standing UC induced by simple repeated administration of DSS (active phase, 4 cycles of 5\% DSS for 7 days and distilled water for 14 days; remission phase, following 120 days of distilled water) according to Cooper et al $(10,21,26)$, and mice were given nimesulide for various periods. Additionally, nimesulide exhibited a significant preventive effect on colorectal carcinogenesis when given during the remission phase via the induction of apoptosis with decreasing oxidative DNA damage (27). However, administration of nimesulide during the active phase exacerbated colitis and did not suppress carcinogenesis $(10,27)$.

In the present study, administration of R-etodolac did not suppress COX-2 protein or mRNA expression in a murine model of UC. These results are consistent with those of previous reports in which R-etodolac was described as lacking COX-inhibitory activity (13). COX-2 overexpression is linked to changes involved in inactivation of E-cadherin and inhibition of apoptosis (28). Even in the normalappearing mucosa in UC patients, diffuse COX-2 expression and high proliferative activity have been demonstrated (29). Aust et al defined the expression patterns of $\beta$-catenin and E-cadherin in UC-related colorectal cancers, and demonstrated that abnormal $\beta$-catenin expression was more closely associated with E-cadherin alterations in UC-related cancers than in sporadic cancers (23). In cancer cell lines, Noda et al confirmed the chemopreventive effect of a COX-2 inhibitor associated with up-regulation of E-cadherin (28). Kolluri et al investigated the effect of R-etodolac in a transgenic mouse prostate adenocarcinoma model, and demonstrated that $\mathrm{R}$ etodolac induced apoptosis selectively in tumor cells via reduction of retinoid $X$ receptor protein levels (30). In the present study, administration of R-etodolac markedly induced expression of E-cadherin and exhibited a preventive effect, which may be independent of COX-2
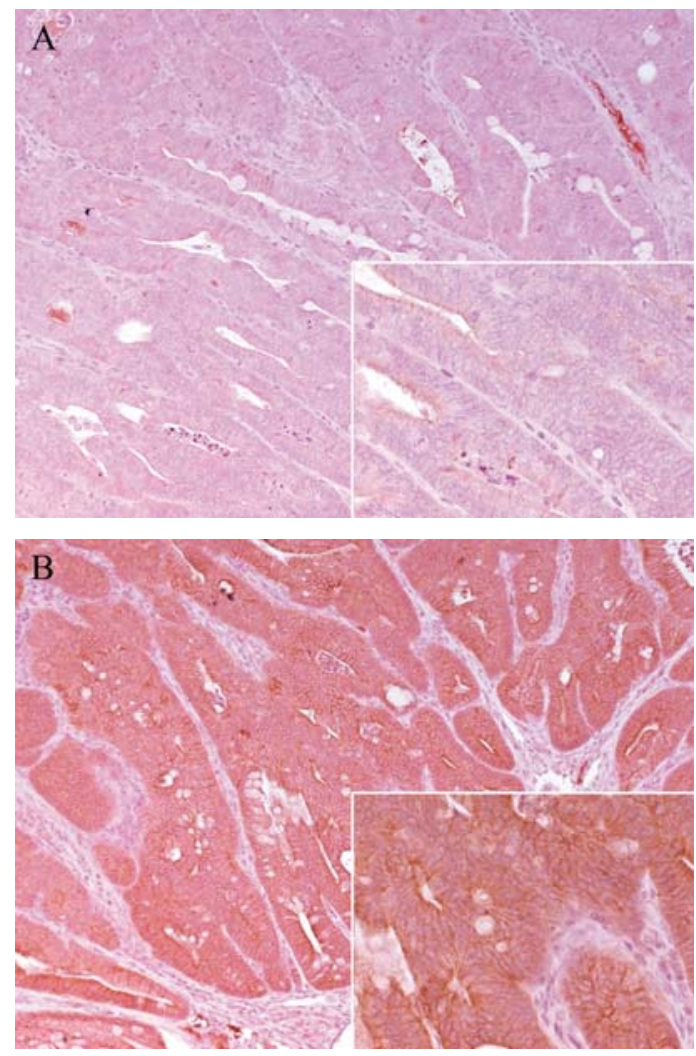

$\mathrm{C}$

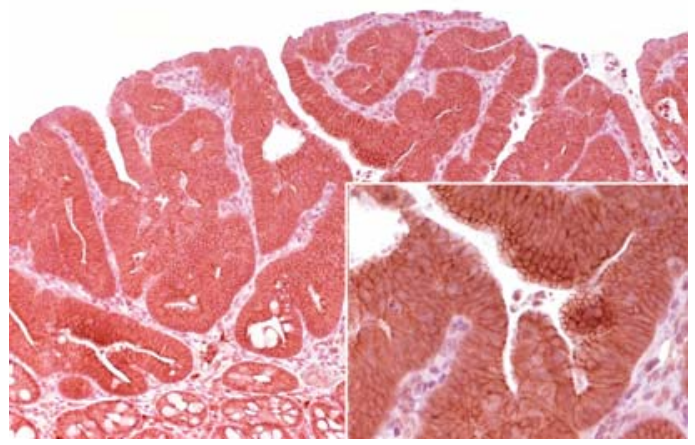

$\mathrm{D}$

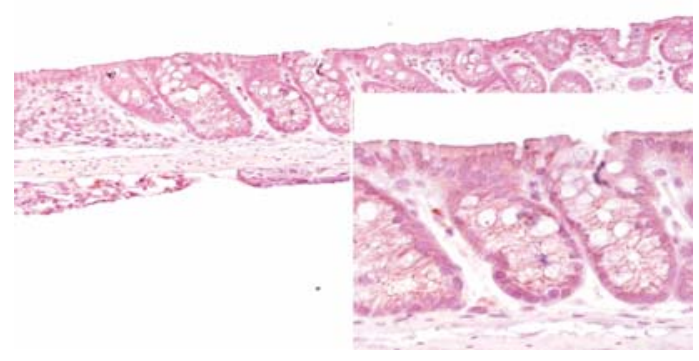

Figure 6. Immunohistochemical analysis of E-cadherin expression in the mouse colon. (A) Disease control (group A); (B) low-dose R-etodolac (group B); (C) high-dose R-etodolac (group C); (D) normal control (group D). Original magnification, x200, x400.

inhibition, on colitis-related mouse colon tumorigenesis. Taken together, we consider that R-etodolac could be useful 
in the prevention of UC-associated neoplasia without exacerbating colitis.

In conclusion, the present data demonstrate that treatment with R-etodolac was effective in diminishing tumorigenesis in an experimental murine model of UC. Although further studies are required to clarify the role of R-etodolac in mouse chronic colitis models, drugs like R-etodolac, which induce up-regulation of E-cadherin independent of COX-2 inhibitory effects, are attractive candidates as preventive agents for UCassociated neoplasia.

\section{References}

1. Thun MJ, Namboodiri MM and Heath CW Jr: Aspirin use and reduced risk of fatal colon cancer. N Eng J Med 325 1593-1596, 1991.

2. Thun MJ, Namboodiri MM, Calle EE, Flanders WD and Heath CW Jr: Aspirin use and risk of fatal cancer. Cancer Res 53: 1322-1327, 1993.

3. Giovannucci E, Egan KM, Hunter DJ, Stampfer MJ, Colditz GA, Willett WC and Speizer FE: Aspirin and the risk of colorectal cancer in women. N Engl J Med 333: 609-614, 1995.

4. Reddy BS, Rao CV, Rivenson A and Kelloff G: Inhibitory effect of aspirin on azoxymethane-induced colon carcinogenesis in F344 rats. Carcinogenesis 14: 1493-1497, 1993.

5. Watson AJ: Chemopreventive effects of NSAIDs against colorectal cancer: regulation of apoptosis and mitosis by $\mathrm{COX}-1$ and COX-2. Histol Histopathol 13: 591-597, 1998.

6. Sakamoto C: Roles of COX-1 and COX-2 in gastrointestinal pathophysiology. J Gastroenterol 33: 618-624, 1998.

7. Ekbom A, Helmick C, Zack M and Adami HO: Ulcerative colitis and colorectal cancer. A population-based study. N Engl J Med 323: 1228-1233, 1990.

8. Miner PB Jr: Factors influencing the relapse of patients with inflammatory bowel disease. Am J Gastroenterol 92: S1-S4, 1997

9. Forrest K, Symmons D and Foster P: Systematic review: is ingestion of paracetamol or non-steroidal anti-inflammatory drugs associated with exacerbations of inflammatory bowel disease? Aliment Pharmacol Ther 20: 1035-1043, 2004.

10. Inoue T, Murano M, Abe Y, Morita E, Murano N, Yasumoto S, Toshina K, Nishikawa T, Maemura K, Hirata I and Katsu K: Therapeutic effect of nimesulide on colorectal carcinogenesis in experimental murine ulcerative colitis. J Gastroenterol Hepatol 22: 1474-1481, 2007.

11. Shi JM, Lai SG, Xu CJ, Duan GL and Li D: Pharmacokinetic difference between S-(+)- and R-(-)-etodolac in rats. Acta Pharmacol Sin 25: 996-999, 2004

12. Demerson CA, Humber LG, Abraham NA, Schilling G, Martel RR and Pace-Asciak C: Resolution of etodolac and antiinflammatory and prostaglandin synthetase inhibiting properties of the enantiomers. J Med Chem 26: 1778-1780, 1983.

13. Behari J, Zeng G, Otruba W, Thompson MD, Muller P, Micsenyi A, Sekhon SS, Leoni L and Monga SP: R-Etodolac decreases beta-catenin levels along with survival and proliferation of hepatoma cells. J Hepatol 46: 849-857, 2007.

14. Okamoto A, Shirakawa T, Bito T, Shigemura K, Hamada K, Gotoh A, Fujisawa M and Kawabata M: Etodolac, a selective cyclooxygenase-2 inhibitor, induces upregulation of E-cadherin and has antitumor effect on human bladder cancer cells in vitro and in vivo. Urology 71: 156-160, 2008.

15. Liu W, Nakamura H, Tsujimura T, Cheng J, Yamamoto T, Iwamoto Y, Imanishi H, Shimomura S, Yamamoto T, Hirasawa T, Inagaki S, Nishiguchi $\mathrm{S}$ and Hada T: Chemoprevention of spontaneous development of hepatocellular carcinomas in fatty liver Shionogi mice by a cyclooxygenase- 2 inhibitor. Cancer Sci 97: 768-773, 2006.
16. Wedemeyer J and Galli SJ: Decreased susceptibility of mast cell-deficient $\mathrm{Kit}(\mathrm{W}) / \mathrm{Kit}(\mathrm{W}-\mathrm{v})$ mice to the development of 1, 2 dimethylhydrazine-induced intestinal tumors. Lab Invest 85: 388-396, 2005.

17. Riddell RH, Goldman H, Ransohof DF, Appleman HD, Fenoglio CM, Haggitt RC, Ahren C, Correa P, Hamilton SR, Morson BC, Sommers SC and Yardley JH: Dysplasia in inflammatory bowel disease: standardized classification with provisional clinical application. Human Pathol 14: 931-968, 1983.

18. Murthy SN, Cooper HS, Shim H, Shah RS, Ibrahim SA and Sedergran DJ: Treatment of dextran sulfate sodium-induced murine colitis by intracolonic cyclosporine. Dig Dis Sci 38: 1722-1734, 1993.

19. Yamauchi T, Watanabe M, Kubota T, Hasegawa H, Ishii Y, Endo T, Kabeshima Y, Yorozuya K, Yamamoto K, Mukai M' and Kitajima M: Cyclooxygenase-2 expression as a new marker for patients with colorectal cancer. Dis Colon Rectum 45: 98-103, 2002.

20. Kotani T, Kobata A, Nakamura E, Amagase K and Takeuchi K: Roles of cyclooxygenase-2 and prostacyclin/IP receptors in mucosal defense against ischemia/reperfusion injury in mouse stomach. J Pharmacol Exp Ther 316: 547-555, 2006.

21. Inoue $\mathrm{T}$, Murano M, Kuramoto T, Ishida K, Kawakami K, Abe Y, Morita E, Murano N, Toshina K, Nishikawa T, Maemura K, Shimamoto C, Hirata I, Katsu K and Higuchi K: Increased proliferation of middle to distal colonic cells during colorectal carcinogenesis in experimental murine ulcerative colitis. Oncol Rep 18: 1457-1462, 2007.

22. Schuhmacher C, Becker I, Oswald S, Atkinson MJ, Nekarda H, Becker KF, Mueller J, Siewert JR and Höfler H: Loss of immunohistochemical E-cadherin expression in colon cancer is not due to structural gene alterations. Virchows Arch 434: 489-495, 1999.

23. Aust DE, Terdiman JP, Willenbucher RF, Chew K, Ferrell L, Florendo C, Molinaro-Clark A, Baretton GB, Löhrs U and Waldman FM: Altered distribution of beta-catenin, and its binding proteins E-cadherin and APC, in ulcerative colitisrelated colorectal cancers. Mod Pathol 14: 29-39, 2001

24. Agoff SN, Brentnall TA, Crispin DA, Taylor SL, Raaka S, Haggitt RC, Reed MW, Afonina IA, Rabinovitch PS, Stevens AC, Freng Z and Bronner MP: The role of cyclooxygenase 2 in ulcerative colitis-associated neoplasia. Am J Pathol 157: 737-745, 2000.

25. Chan AT, Ogino S and Fuchs CS: Aspirin and the risk of colorectal cancer in relation to the expression of COX-2. N Eng J Med 356: 2131-2142, 2007.

26. Cooper HS, Murthy S, Kido K, Yoshitake H and Flanigan A: Dysplasia and cancer in the dextran sulfate sodium mouse colitis model. Relevance to colitis-associated neoplasia in the human: a study of histopathology, B-catenin and p53 expression and the role of inflammation. Carcinogenesis 21: 757-768, 2000.

27. Inoue T, Murano M, Kakimoto K, Okada T, Kawakami K, Ishida K, Abe Y, Morita E, Murano N, Toshina K, Maemura K, Hirata I and Higuchi K: Therapeutic effect of a cyclooxygenase-2 selective inhibitor on colitis induced tumors. (in Japanese) Ulcer Res 35: 87-90, 2008.

28. Noda M, Tatsumi Y, Tomizawa M, Takama T, Mitsufuji S, Sugihara H, Kashima K and Hattori T: Effects of etodolac, a selective cyclooxygenase-2 inhibitor, on the expression of E-cadherin-catenin complexes in gastrointestinal cell lines. J Gastroenterol 37: 896-904, 2002.

29. Shinozaki M, Watanabe T, Kubota Y, Sawada T, Nagawa H and Muto T: High proliferative activity is associated with dysplasia in ulcerative colitis. Dis Colon Rectum 43: S34-S39, 2000.

30. Kolluri SK, Corr M, James SY, Bernasconi M, Lu D, Liu W, Cottam HB, Leoni LM, Carson DA and Zhang XK: The Renantiomer of the non-steroidal antiinflammatory drug etodolac binds retinoid $X$ receptor and induces tumor-selective apoptosis. Proc Natl Acad Sci USA 102: 2525-2530, 2005. 